\title{
Sensitivity of lake thermal and mixing dynamics to climate change
}

\author{
Jonathan B. Butcher • Daniel Nover • \\ Thomas E. Johnson • Christopher M. Clark
}

Received: 2 August 2014 / Accepted: 7 January 2015 / Published online: 19 January 2015

(C) The Author(s) 2015. This article is published with open access at Springerlink.com

\begin{abstract}
Warming-induced changes in lake thermal and mixing regimes present risks to water quality and ecosystem services provided by U.S. lakes and reservoirs. Modulation of responses by different physical and hydroclimatic settings are not well understood. We explore the potential effects of climate change on 27 lake "archetypes" representative of a range of lakes and reservoirs occurring throughout the U.S. Archetypes are based on different combinations of depth, surface area, and water clarity. LISSS, a one-dimensional dynamic thermal simulation model, is applied to assess lake response to multiple mid-21st century change scenarios applied to nine baseline climate series from different hydroclimatic regions of the U.S. Results show surface water temperature increases of about $77 \%$ of increase in average air temperature change. Bottom temperature changes are less (around $30 \%$ ) for deep lakes and in regions that maintain mid-winter air temperatures below freezing. Significant decreases in length of ice cover are projected, and the extent and strength of stratification will increase throughout the U.S., with systematic differences associated with depth, surface area, and clarity. These projected responses suggest a range of future challenges that lake managers are likely to face. Changes in thermal and mixing dynamics suggest increased risk of summer
\end{abstract}

Electronic supplementary material The online version of this article (doi:10.1007/s10584-015-1326-1) contains supplementary material, which is available to authorized users.

J. B. Butcher $(\bowtie)$

Tetra Tech, Inc., PO Box 14409, Research Triangle Park, NC 27709, USA

e-mail: jon.butcher@tetratech.com

D. Nover • T. E. Johnson • C. M. Clark

U.S. Environmental Protection Agency, Office of Research and Development, Washington, DC, USA

D. Nover

e-mail: dmnover@gmail.com

T. E. Johnson

e-mail: Johnson.Thomas@epa.gov

C. M. Clark

e-mail: Clark.Christopher@epa.gov

Present Address:

D. Nover

U.S. Agency for International Development, West African Regional Office, Accra, Ghana 
hypoxic conditions and cyanobacterial blooms. Increased water temperatures above the summer thermocline could be a problem for cold water fisheries management in many lakes. Climate-induced changes in water balance and mass inputs of nutrients may further exacerbate the vulnerability of lakes to climate change.

\section{Introduction}

Thermal and mixing dynamics in lakes are forced by energy exchanges with the atmosphere. Increased average air temperature over the past three decades has been associated with increases in mean lake temperature (e.g., Coates et al. 2006) and decreased ice cover (Magnuson et al. 2000). Warming of surface waters has increased the strength of thermal stratification (Rempfer et al. 2010), which leads to reduced mixing and, in some deeper lakes, a decrease in summer temperatures at depth (Livingstone 2003; Coates et al. 2006).

Climate change will affect air-water energy exchanges and further alter the temperature regime and mixing of lakes. In addition to heat exchanges, the response is modulated by lake geometry, wind stress, and light extinction rates in the water column. Lake surface area and depth affect strength of stratification (Stefan et al. 1996). Decreased wind speed and increased light attenuation are observed to increase stratification and reduce whole-lake average temperature (Tanentzap et al. 2008). Increased water clarity can warm deeper waters (Stefan et al. 1996). Reduced light penetration decreases mixing depth and can cause cooling in deeper water (Hocking and Straškraba 1999), while summer surface water temperatures may increase or decline depending on the entrainment of colder hypolimnetic water (Persson and Jones 2008).

Schmid et al. (2014) evaluated the sensitivity of lake surface temperatures to climate change and predicted anomalies in lake surface equilibrium temperature in the range of $2-5^{\circ} \mathrm{C}$ by the end of the 21 st century. They estimated that surface equilibrium temperatures would increase by 70 to $85 \%$ of air temperature changes, with most of the residual between-lake variance attributed to changes in relative humidity and, to a lesser extent, wind speed. Fang and Stefan (1996) used a daily-scale one-dimensional temperature model to investigate potential climate-induced changes in thermal profiles of U.S. lakes under a doubling of $\mathrm{CO}_{2}$ concentrations and predict relative sensitivities for surface water temperature similar to Schmid et al., accompanied by a decrease in ice cover, strong increases in hypolimnetic temperatures, and an increase in stratification strength, dependent on lake geometry. Their study used only a single GCM on a coarse $\left(3.75^{\circ} \times 3.75^{\circ}\right)$ scale and simulated response at a daily time step, which may obscure the details of mixing events that occur in response to diel variations in air temperature and solar energy input.

Longer periods of stratification increase the risk of hypolimnetic anoxia (Foley et al. 2012), which in turn increases the rate of recycling of phosphorus from lake sediment (Wilhelm and Adrian 2008). Lake ecosystems are vulnerable to climate change because many lacustrine species have limited abilities to disperse to lakes with favorable conditions (Woodward et al. 2010) and reorganization of food webs may be a consequence of warming of lakes. Long-term temperature manipulation of experimental ponds in Denmark resulted in a shift in community structure to more turbid, plankton-dominated systems as temperature increased (Meerhoff et al. 2007). The retrospective study of Rühland et al. (2008) and experimental studies of Strecker et al. (2004) demonstrate that warming and changes in ice cover cause reorganization of phytoplankton and zooplankton communities in minimally disturbed lakes. Interlandi et al. (1999), studying lakes in the Yellowstone region, showed that changes in timing of water column mixing regulated the abundance of phytoplankton groups by controlling the relative timing of nutrient recycling versus light availability. Climate change is also likely to increase the spread of non-native invasive species (Rahel and Olden 2008; Holzapfel and Vinebrooke 2005). 
These changes may impact human uses as well, with increased risk of cyanobacterial blooms, increased mobilization of soluble metals, and potential issues for potable water treatability as hypolimnetic oxygen depletion increases. Harmful cyanobacterial blooms are driven by increased anthropogenic nutrient loads, but are also associated with summer heat waves (Jöhnk et al. 2008). Paerl et al. (2011) summarize important feedbacks with climate warming that are likely to favor cyanobacteria. An improved understanding of controls on lake sensitivity to climate change will help guide adaptation strategies.

In this study we focus on the responses of lake thermal structure and mixing regime to climate change, which in turn determine temperatures at the thermocline and in bottom water, and are expected to be less closely coupled to air temperature than lake surface temperature. The study builds on the work of Fang and Stefan (2009) by using a similar set of lake archetypes, but extends their analyses by evaluating an ensemble of mid-21st century climate change scenarios including a complete set of internally consistent projected meteorological time series. We evaluate lake response to integrated climate projections that include simultaneous changes in a full suite of weather variables generated by dynamical downscaling at a $50 \times 50 \mathrm{~km}$ scale and implement a lake simulation model forced at an hourly scale to resolve diel cycles of energy exchanges and shallow mixing events. We focus on lake thermal structure because it determines (1) the occurrence, intensity, and frequency of stratification and mixing events, (2) the percentage of lake volume that is mixed and in contact with the atmosphere, (3) the distribution of thermal habitat zones relative to the mixed, oxygenated zone of stratified lakes, and (4) the rates and timing of recycling of nutrients and other pollutants from lake sediments into the photic zone.

\section{Methods}

Factors potentially influencing lake response to climate change include baseline climate, changes in climate forcing (energy and flow/mass inputs), lake geometry, and water clarity (which controls the depth of light and associated energy penetration into the water column). We simulated 1701 scenarios of lake thermal dynamics, where the scenarios consist of 27 lake archetypes at each of 9 baseline climates (locations representing different hydroclimatic regimes) and for 7 climate scenarios (baseline (1970-2000) climate plus six mid-century (2041-2070) climate projections).

\subsection{Lake archetypes}

The National Lakes Database (NLD; U.S. EPA 2009) contains information on surface area, maximum depth, and water clarity for 1148 unique lakes (out of an estimated national population of 68,223 ), ranging in area from $<0.05$ to $1675 \mathrm{~km}^{2}$ and in maximum depth from $<1$ to $97 \mathrm{~m}$. The range of lake types is represented through a set of hypothetical archetypes that follow the scheme of Fang and Stefan (2009), who used a $3 \times 3 \times 3$ experimental design based on small, medium, and large depth, surface area, and water clarity as Secchi depth (see Table S-1 in online supplement). The statistical sample of lakes within the NLD contains lakes that fall into all 27 of the archetype categories, although the largest fraction (22\%) is in the shallow, small, and turbid category.

\subsection{Lake thermal model}

One-dimensional thermal diffusion models with parameterized eddy diffusivity, such as the Hostetler model (Hostetler and Bartlein 1990) and the MINLAKE model 
(Fang and Stefan 1996) have been shown to be suitable to describing thermal structure in small to moderate sized lakes, although they may under-predict mixing for large and deep lakes affected by additional mechanisms such as internal seiches (Perroud et al. 2009; Stepanenko et al. 2013). In this study we use a corrected and enhanced version of the Hostetler 1-D lake thermal model code known as LISSS (Lake, Ice, Snow, and Sediment Simulator; Subin et al. 2012). LISSS was developed for the Community Land Model 4 (CLM4; Lawrence et al. 2011), which is the land component of the Community Earth System Model 1 (CESM1; Gent et al. 2011).

LISSS enhances the Hostetler model by (1) providing a comprehensive treatment of snow including grain size changes with aging and the effects of aerosol deposition on albedo (Flanner et al. 2007), (2) explicitly simulating freezing, melting, and ice physics, (3) including a sediment thermal submodel, (4) improving the parameterization of lake surface properties such as roughness lengths, and (5) improving the simulation of density-driven mixing events. LISSS solves the 1D thermal diffusion equation for lake water and ice, overlying snow (when present), and underlying substrate, then simulates vertical mixing caused by wind-driven eddies, convection, molecular diffusion, and unresolved 3D mixing processes (following Fang and Stefan 1996). Atmosphere-lake coupling includes momentum transfer based on fetch-limited friction velocity. After balancing energy fluxes and solving the diffusion equations, LISSS performs full or partial mixing of the water column based on density of adjacent layers. Total lake volume is considered fixed, lateral inflows and outflows are not explicit, and volume changes from direct precipitation, melting snow, and evaporation are immediately balanced as outflows. As implemented in this study, the model includes 25 lake layers, 15 ground layers, and up to 5 snow layers. LISSS has been shown to provide an accurate representation of water temperature and surface fluxes at three small temperate and boreal lakes where extensive observational data was available and also performed well at predicting water temperature and/or ice and snow thicknesses for ten other lakes where less comprehensive forcing observations were available (Subin et al. 2012).

LISSS is written as a FORTRAN90 module embedded within the larger CLM4 and uses routines from many other parts of CLM4. It is also designed to receive energy and mass forcings from the CESM1. We revised the code to operate in a standalone mode with forcing by user-specified meteorological time series. Code performance was verified by comparison to results of test cases reported by Subin et al. (2012) for Sparkling Lake $\left(46.01{ }^{\circ} \mathrm{N},-89.70{ }^{\circ} \mathrm{E}\right.$; Martynov et al. 2010); Kossenblatter (52.13 ${ }^{\circ} \mathrm{N}, 14.1^{\circ} \mathrm{E}$; Beyrich et al. 2006), and ValkeaKotinen (61.24 ${ }^{\circ} \mathrm{N}, 25.06^{\circ} \mathrm{E}$; Nordbo et al. 2011).

\subsection{Climate forcing}

Meteorological forcing required for LISSS includes air temperature, pressure, precipitation, humidity, wind speed, shortwave radiation, and downward longwave radiation. Meteorological time series used here are a subset of those we developed for a U.S. EPA study of potential climate impacts on hydrology and water quality in large U.S. watersheds (Johnson et al. 2012; U.S. EPA 2013). To represent different baseline climate conditions we selected a set of nine first-order weather stations located in different hydroclimatic regions ranging from humid subtropical Tampa, FL (mean temperature $22.3^{\circ} \mathrm{C}$ ) to cold, high-elevation Sugarloaf Reservoir, $\mathrm{CO}$ (mean temperature $4.6^{\circ} \mathrm{C}$; see Fig. 1 and detailed characteristics summarized in supplementary Table S-2 and Figure S-1 in the supplement).

Mid-21st century climate change scenarios are based on six high-resolution simulations archived by the North American Regional Climate Change Assessment Program (NARCCAP; Mearns et al. 2009) for 2041-2070. The NARCCAP simulations use regional climate models (RCMs) to dynamically downscale output from Global Climate Models (GCMs) used in the 


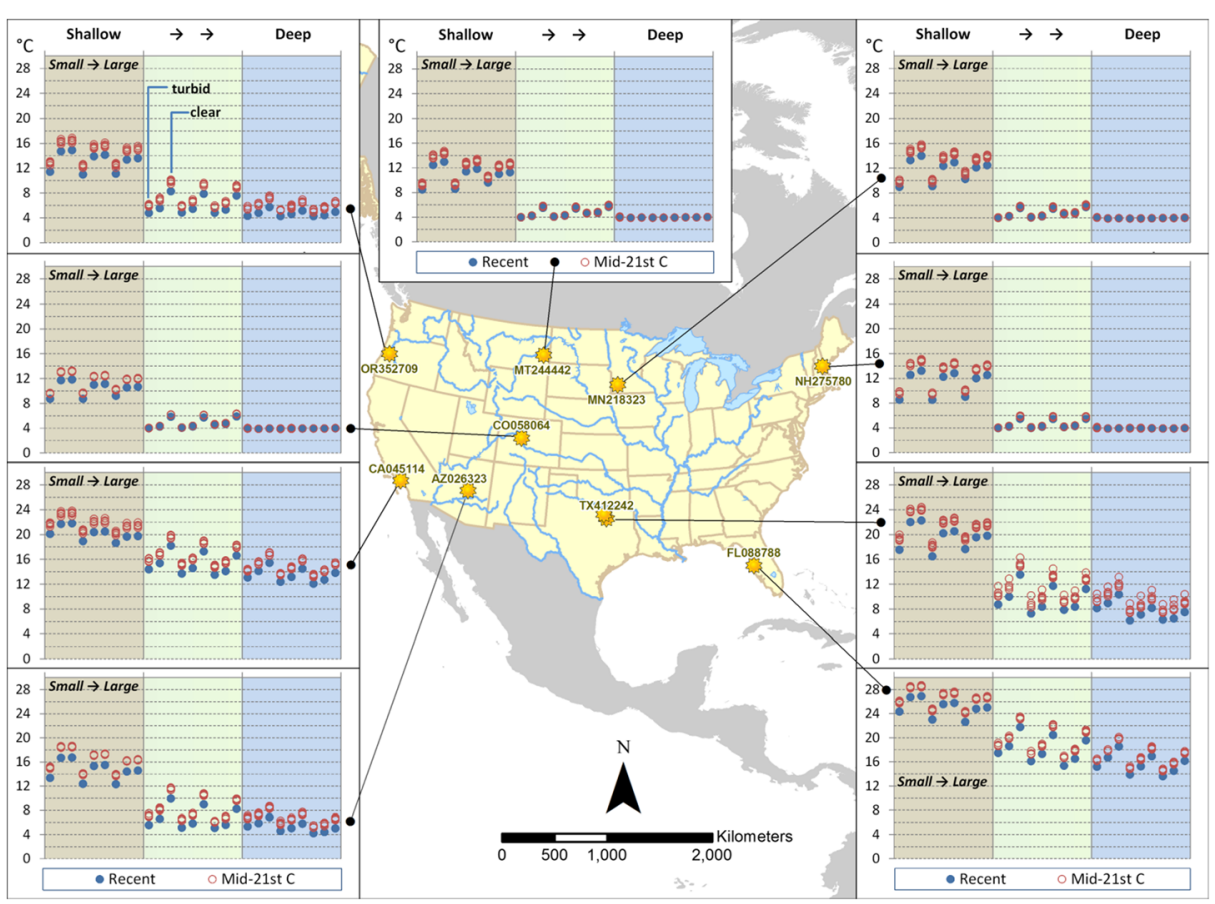

Fig. 1 Average bottom water temperature distribution $\left({ }^{\circ} \mathrm{C}\right)$ for baseline and mid-21st century. The three major sub-panels in each graph represent shallow, medium, and deep lakes. Within each of the depth ranges there are three sets of three results representing short, medium, and long fetch (or small, medium, and large surface area). Finally, within each group of fetch length, results are shown for turbid, medium clarity, and clear lakes. See Table S-11 in the online supplement for detailed results

Intergovernmental Panel on Climate Change (IPCC) 4th Assessment Report (IPCC 2007) to a $50 \times 50 \mathrm{~km}^{2}$ grid over North America. Table S-3 identifies the GCM - RCM combinations included in this study.

We created hourly meteorological time series representing each NARCCAP climate change scenario using a change factor approach (Anandhi et al. 2011). Monthly change statistics were calculated for each meteorological variable as the difference between baseline (1971-2000) and projected future (2041-2070) conditions. Temperature adjustments apply additive monthly change factors to historical observations, while multiplicative monthly change factors are used for other variables, including adjustments to represent precipitation intensification (see details in the online supplement). Baseline meteorological data for all weather stations were acquired from the 2006 BASINS Meteorological Database (U.S. EPA 2008).

\section{Results}

Output for each model scenario contains 30 years of data (generated after 30-year model spinup) for 25 depth levels. We focus on results for water temperature, ice cover, and stratification strength; additional analyses, including energy balance feedback with the atmosphere and sensitivity to continued warming beyond the mid- 21 st century, are contained in the online supplement. 


\subsection{Response of water temperature}

Each NARCCAP climate scenario shows increasing average air temperature (ranging from $1.8{ }^{\circ} \mathrm{C}$ to $2.7^{\circ} \mathrm{C}$ at the nine climate locations, with the largest increases at the high-altitude station in Colorado), while changes in other meteorological factors vary. Changes in average surface water temperatures are closely tied to changes in annual air temperature with similar increases for all baseline climates (Figure S-3). The ratio of change in water temperature to change in air temperature is $77 \%$, consistent with Schmid et al. (2014). In contrast, hypolimnetic temperature responds to a variety of complex interactions influenced by lake archetype characteristics (Fig. 1; see also Table S-11). Unlike surface temperature, hypolimnetic temperature responds to a complex interaction between energy exchanges and stratification. Total thermal inputs increase, but so does resistance to mixing. When and at what depth the thermocline develops and the depth of light penetration relative to the thermocline influence hypolimnetic temperature. Lake bottom water temperature declines with increased depth, increases with increasing water clarity (which lets more light penetrate to the bottom), and decreases with fetch.

Simulated future changes in summer average bottom water temperature are correlated with the current bottom water temperature, which integrates the effects of lake geometry (Fig. 2a). Lakes that show relatively small changes in bottom temperature are those that are deeper and have significant ice cover with winter bottom temperatures that are stable near the maximum density of water just below $4{ }^{\circ} \mathrm{C}$. Changes in average bottom temperature vary strongly with lake depth and Secchi depth or transparency. The average increase in summer bottom temperature per change in annual average air temperature for shallow lakes (maximum depth $4 \mathrm{~m}$ ) is $76 \%$, while the ratio for deep lakes (maximum depth $24 \mathrm{~m}$ ) is $37 \%$. The change in average integrated water temperature is $26-36 \%$ of change in average air temperature for lakes that maintain significant amounts of ice cover and $62-83 \%$ for lakes that do not. Summer average hypolimnetic temperature can be predicted as a function of annual average air
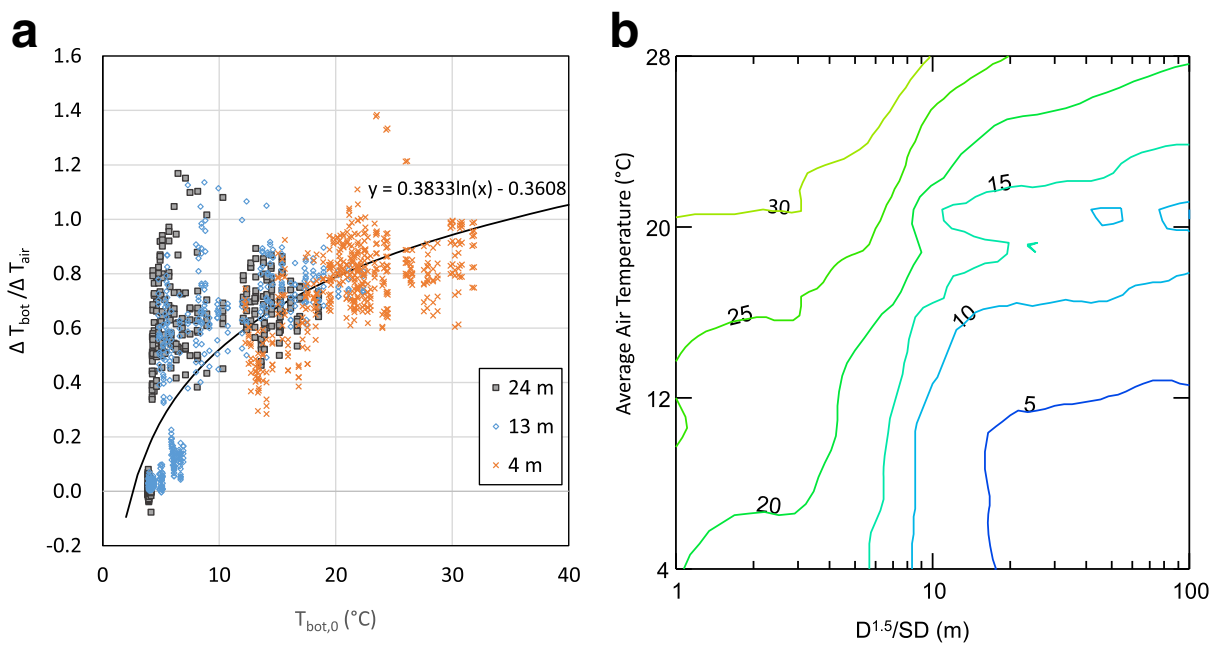

Fig. 2 Summer bottom water temperature: a Ratio of change in future bottom water temperature $\left(\Delta \mathrm{T}_{\text {bot }}\right)$ to change in annual average air temperature $\left(\Delta \mathrm{T}_{\text {air }}\right)$ relative to existing bottom temperature $\left(\mathrm{T}_{\text {bot, } 0}\right)$ and lake maximum depth; b summer bottom water temperature as a function of average annual air temperature and the ratio of lake depth to Secchi depth times the square root of lake depth $\left(\mathrm{D}^{1.5} / \mathrm{SD}\right)$ 
temperature and a composite variable (the ratio of depth to Secchi depth times the square root of depth) that appears to index the joint effects of depth of light penetration and depth-related resistance to mixing, with residual noise due to differences between sites and weather scenarios in wind stress, solar radiation input, and relative humidity (Fig. 2b).

We investigate the correlation of projected water temperature to lake archetype and climate forcing variables through the use of analysis of variance, Pearson correlation, and Classification and Regression Trees (CART) in the online supplement. The top two factors for classifying change in surface water temperature are air temperature and solar radiation, while the factors best discriminating change in bottom temperature are depth, change in atmospheric temperature, and change in wind.

Sample depth-time isotherms are shown in Figure S-2 for the baseline climate of New Durham, NH with lake archetypes 14 (medium depth and fetch) and 8 (shallow, long fetch). The deeper archetype exhibits spring and fall vertical mixing, while the archetype with the smaller depth:area ratio is mixed repeatedly throughout the year.

\subsection{Response of winter ice cover}

For northern lakes, the extent of winter ice and the depth of overlying snow pack are important as ice cover inhibits gas exchange with the atmosphere, while ice and snow limit solar radiation input that supports photosynthesis and oxygen production. Ice and snow cover also insulate the water below and reflect solar radiation, leading to later spring warm up and lower water temperatures persisting into the summer.

The nine baseline climates include four locations where winter ice cover is prevalent. Projected changes by the mid-21st century (Figure S-4) include a reduction in ice cover at these locations averaging 20-30 days per year, with an average of up to 41 days per year for some scenarios at the New Hampshire site. Despite these large changes, all four of the coldweather sites remain ice covered for more than 70 days per year at mid-century. The majority of the changes by mid-century are projected to occur in the spring, with ice in delayed about a week, but ice out occurring two to four weeks earlier. Lake archetype plays an important role in influencing the baseline length of ice coverage but has only a small influence (less than 1 day) in the differential response to climate change scenarios.

Average ice thickness on days when ice is present is also projected to decrease, as does the projected thickness of snow on top of ice, allowing greater light penetration. There is a particularly strong (38\%) reduction in snow thickness at the New Durham, New Hampshire station that likely contributes to the earlier ice out projected for this station.

\subsection{Response of thermal stratification}

The LISSS model enables direct evaluation of the intensity and duration of stratification and the frequency of mixing events set off by thermal instability and wind stress. Stratification strength is summarized via the one-dimensional analogue of Schmidt stability $\left(\mathrm{J} / \mathrm{m}^{2}\right.$; Idso 1973). Schmidt stability is a measure of the energy required to mix the water column and thus varies strongly with depth (model average of $400 \mathrm{~J} / \mathrm{m}^{2}$ at $4 \mathrm{~m}$ depth to $45.470 \mathrm{~J} / \mathrm{m}^{2}$ at $24 \mathrm{~m}$ depth under current climate; Table 1 ). Changes in stability vary by location and lake archetype, with larger increases in deeper and more turbid lakes; however, the percentage changes is relatively consistent across depth classes (mean $18.9 \%$, standard deviation $8.0 \%$; see Table 1). The open water stratification ratio, defined as the fraction of time when the surface layer temperature is more than $1{ }^{\circ} \mathrm{C}$ greater than the bottom layer temperature, also increases at most stations. As discussed in the online supplement, increases in air temperature and insolation are 
Table 1 Projected changes by mid-21st century in summer (May-October) Schmidt stability $\left(\mathrm{J} / \mathrm{m}^{2}\right)$

\begin{tabular}{|c|c|c|c|c|c|c|c|}
\hline \multirow[t]{2}{*}{ Climate station } & \multicolumn{2}{|c|}{ Shallow (4 m) } & \multicolumn{2}{|c|}{ Medium (13 m) } & \multicolumn{2}{|c|}{ Deep (24) } & \multirow[t]{2}{*}{ Percent change } \\
\hline & Current & $2050 \mathrm{~s}$ & Current & $2050 \mathrm{~s}$ & Current & $2050 \mathrm{~s}$ & \\
\hline Tampa, FL088788 & 333 & 366 & 25,581 & 27,781 & 74,240 & 81,359 & $9.3 \%$ \\
\hline New Durham, NH575780 & 601 & 722 & 16,215 & 20,311 & 34,538 & 43,433 & $23.7 \%$ \\
\hline Tracy, MN218323 & 560 & 693 & 18,036 & 22,032 & 39,160 & 47,704 & $22.6 \%$ \\
\hline Dallas, TX412242/412404 & 517 & 572 & 30,053 & 33,525 & 72,834 & 82,428 & $11.8 \%$ \\
\hline Ismay, MT244442 & 441 & 551 & 15,002 & 18,540 & 33,087 & 40,595 & $23.7 \%$ \\
\hline Payson, AZ026323 & 362 & 418 & 18,996 & 22,182 & 46,027 & 54,770 & $17.1 \%$ \\
\hline Eugene, OR325709 & 354 & 400 & 15,223 & 17,702 & 35,395 & 42,045 & $16.0 \%$ \\
\hline Sugarloaf Reservoir, CO058064 & 263 & 335 & 11,694 & 14,814 & 26,945 & 33,873 & $26.5 \%$ \\
\hline Los Angeles, CA045114 & 171 & 197 & 15,409 & 17,243 & 47,017 & 52,861 & $13.2 \%$ \\
\hline
\end{tabular}

positively correlated with increases in stratification. CART analysis suggests that changes in water clarity (Secchi depth) is also an important factor for Schmidt stability in shallow lakes and deep lakes, while wind is an important factor in medium depth and deep lakes.

\section{Discussion}

This comprehensive modeling study using realistic weather scenarios for the mid-21st century finds that surface water temperatures and Schmidt stability will increase in lakes with a variety of geometries and water quality conditions under future climate. Bottom water temperature will respond in more complex and variable ways due to the interaction of energy inputs and mixing/stability. Results suggest a plausible range of changes that can be anticipated for lakes in different regions of the U.S. by the mid-21st century. These changes vary with different baseline climate conditions (i.e., location), but also according to the physical characteristics of lakes, including depth, fetch, and water clarity. Lakes with greater depth will be more resistant to increases in total thermal content. Lakes with lower water clarity (smaller Secchi depth and higher turbidity) will have temperature increases focused in surface layers. For northern lakes, significant reductions in winter ice cover are projected. These trends will be further amplified as air temperatures increase beyond the mid-21st century (see supplement) and will present challenges for adaptation and management of lakes.

Increased surface water temperature increases thermal resistance to vertical mixing. Changes in wind could also have an important effect, with increased wind stress potentially counteracting the increase in thermal stratification; however, LISSS simulations show little impact from changes in wind speed for the mid-21st century. (Projected changes in monthly average wind speed range from $-15 \%$ to $+12 \%$ with a median of $-1 \%$ for the stations used in this study.)

Projected changes in lake temperature, stratification strength, and mixing dynamics under future climate are likely to induce a variety of impacts on chemistry and ecology of lakes, which in turn have implications for adaptation strategies and management of lakes. LISSS does not explicitly simulate water quality; however, changes in thermal and mixing regime have direct implications for water quality. For dissolved gases, including dissolved oxygen (DO), there will be greater reaeration opportunity in colder climates in the winter, due to reduced ice cover, but less ability to reaerate deeper waters in summer due to increased stability. Stability is projected to increase under future climate at all locations, increasing rates of hypolimnetic oxygen 
depletion, which in turn could facilitate regeneration of soluble phosphorus and metals from lake sediments. Altered timing of fall overturn may play a role in how the effects of such releases are expressed; for instance, later fall overturn could focus nutrient replenishment in the epilimnion to periods of lower light availability. Simulations in this study also suggest potential changes in ice out timing and mixing regimes that could result in shifts toward more turbid, plankton-dominated systems with an increased risk of cyanobacterial blooms.

During periods of high thermal stress in stratified lakes, fish survive in cooler waters at the bottom of the mixed zone that is in contact with the atmosphere (e.g., Coutant 1985). An index for effects of lake physical changes on fish is the maximum temperature in the water layer immediately above the thermocline (defined as the layer containing the maximum rate of change in temperature with depth under predawn conditions). Critical thermal maxima for cold water fish species are typically cited in the range of $29-32{ }^{\circ} \mathrm{C}$ (Wismer and Christie 1987). Fish sensitivity to thermal stress is often evaluated with the "7DADMax"- the 7-day average of daily maximum temperatures. The 7DADMax just above the thermocline results from the interaction of a variety of factors that control heating of the water column and the depth of the thermocline. More turbid lakes generally have lower 7DADMax temperatures at the thermocline because light energy does not penetrate as deeply. The relationship between medium clarity and clear lakes varies as it depends on the relationship between light penetration, depth of the thermocline, and the stability of stratification. Despite these differences among archetypes, the average change by site in the thermocline 7DADMax falls into a relatively small range, from an increase of $1.7^{\circ} \mathrm{C}$ for Tampa, Florida to more than $2.3^{\circ} \mathrm{C}$ for Tracy, Minnesota.

The predicted changes in 7DADMax temperatures are sufficient to raise concerns for the health of many fisheries, especially in small and shallow lakes. At the New Durham, New Hampshire and Tracy, Minnesota sites, many of the shallow lakes are projected to have 7DADMax values that increase from well below $30{ }^{\circ} \mathrm{C}$ to values in the $31-32{ }^{\circ} \mathrm{C}$ range, which is an approximate tolerance limit for many colder water species.

This analysis provides improved understanding of potential lake sensitivity to climate change that may help guide adaptation strategies. As with any study of this type, results are conditional on the methods, models, and scenarios evaluated. The 1D LISSS model does not address residence time, which has an important role in the response of real lakes. This study also does not address climate-related changes in watershed runoff and associated pollutant transport. Watershed simulations driven by the same dynamically downscaled mid-21st century climate projections used in this paper show substantial changes in the expected amount and seasonal timing of freshwater flows (U.S. EPA 2013). In many areas there will be less snowpack, greater winter flows, and lower summer flows. More intense runoff events are projected with increased watershed loads of sediment and nutrients in many areas. These changes in mass inputs may have important consequences for lake health. Their expression will be mediated in part by the changes in thermal structure described in this paper, but a full analysis suitable for informing adaptation planning at the site level will need to evaluate both energy and mass, and do so in the context of real lakes that operate in three dimensions.

Acknowledgments We thank Dr. Zachary Subin (Princeton Environmental Institute) for generously sharing the LISSS model code. We also thank Dr. Victor Stepanenko (Lomonosov Moscow State University), Dr. Andrey Martynov (Université du Québec à Montréal), Dr. Annika Nordbo, Dr. Anne Ojala, and Dr. Jussi Huotari (University of Helsinki) for allowing use of their detailed lake energy flux datasets in verification of our implementation of the LISSS code. Dr. Seth McGinnis of the National Center for Atmospheric Research (NCAR) processed the NARC CAP output into change statistics for use in the development of future climate scenarios. NCAR is supported by the National Science Foundation. Funding for this work was provided by the U.S. Environmental Protection Agency, Office of Research and Development. The views expressed in this paper represent those of the authors and do not necessarily reflect the views or policies of the U.S. Environmental Protection Agency. 
Open Access This article is distributed under the terms of the Creative Commons Attribution License which permits any use, distribution, and reproduction in any medium, provided the original author(s) and the source are credited.

\section{References}

Anandhi A, Frei A, Pierson DC, Schneiderman EM, Zion MS, Lounsbury D, Matonse AH (2011) Examination of change factor methodologies for climate change impact assessment. Water Resour Res 47, W03501. doi: 10.1029/2010WR009104

Beyrich F, Leps JP, Mauder M, Bange J, Foken T, Huneke S, Lohse H, Lüdi A, Meijninger WML, Mironov D, Weisensee U, Zittel P (2006) Area-averaged surface fluxes over the litfass region based on eddy-covariance measurements. Bound-Layer Meteorol 121:33-65. doi:10.1007/s10546-006-9052-X

Coates R, Perez-Losada J, Schladow G, Richards R, Goldman C (2006) The warming of Lake Tahoe. Clim Chang 76:121-148. doi:10.1007/s10584-005-9006-1

Coutant CC (1985) Striped bass, temperature, and dissolved oxygen: a speculative hypothesis for environmental risk. Trans Am Fish Soc 114:31-61. doi:10.1577/1548-8659(1985)114<31:SBTADO>2.0.CO;2

Fang X, Stefan HG (1996) Development and validation of the water quality model MINLAKE96 with winter data, Project Report 390, St. Anthony Falls Laboratory, Univ. of Minnesota

Fang X, Stefan HG (2009) Simulations of climate effects on water temperature, dissolved oxygen, and ice and snow covers in lakes of the contiguous United States under past and future climate scenarios. Limnol Oceanogr 54:2359-2370. doi:10.4319/lo.2009.54.6_part_2.2359

Flanner MG, Zender CS, Randerson JT, Rasch PJ (2007) Present-day climate forcing and response from black carbon in snow. J Geophys Res 112, D11202. doi:10.1029/2006JD008003

Foley B, Jones ID, Maberly SC, Rippey B (2012) Long-term changes in oxygen depletion in a small temperate lake: effects of climate change and eutrophication. Freshw Biol 57:278-289. doi:10.1111/j.1365-2427.2011.02662.x

Gent PR, Danabasoglu G, Donner LJ, Holland MM, Hunke EC, Jayne SR, Lawrence DM, Neale RB, Rasch PJ, Vertenstein M, Worley PH, Yang ZL, Zhang M (2011) The community climate system model version 4. J Climatol 24:4973-4991. doi:10.1175/2011JCLI4083.1

Hocking GC, Straškraba M (1999) The effect of light extinction on thermal stratification in reservoirs and lakes. Int Rev Hydrobiol 84:535-556. doi:10.1002/iroh.199900046

Holzapfel AM, Vinebrooke RD (2005) Environmental warming increases invasion potential of alpine lake communities by imported species. Glob Chang Biol 11:2009-2015. doi:10.1111/j. 1365-2486.2005.001057.x

Hostetler SW, Bartlein PJ (1990) Simulation of lake evaporation with application to modeling lake level variations of Harney-Malheur Lake, Oregon. Water Resour Res 26:2603-2612. doi:10.1029/ WR026i010p02603

Idso SB (1973) On the concept of lake stability. Limnol Oceanogr 18:681-683. doi:10.4319/lo.1973.18.4.0681

Intergovernmental Panel on Climate Change (IPCC) (2007) Climate change 2007: the physical science basis. Contribution of Working Group I to the Fourth Assessment Report of the Intergovernmental Panel on Climate Change. Cambridge University Press

Interlandi SJ, Kilham SS, Theriot EC (1999) Responses of phytoplankton to varied resource availability in large lakes of the Greater Yellowstone Ecosystem. Limnol Oceanogr 44:668-682. doi:10.4319/lo.1999.44.3.0668

Jöhnk KD, Huisman J, Sharples J, Sommeijer B, Visser M, Strooms JM (2008) Summer heatwaves promote blooms of harmful cyanobacteria. Glob Chang Biol 14:495-512. doi:10.1111/j.1365-2486.2007.01510.x

Johnson TE, Butcher JB, Parker A, Weaver CP (2012) Investigating the sensitivity of U.S. streamflow and water quality to climate change: the EPA Global Change Research Program's "20 Watersheds" project. J Water Resour Plan Manag 138:453-464. doi:10.1061/(ASCE)WR.1943-5452.000017

Lawrence DM, Oleson KW, Flanner MG, Thornton PE, Swenson SC, Lawrence PJ, Zeng X, Yang ZL, Levis S, Sakaguchi K, Bonan GB, Slater AG (2011) Parameterization improvements and functional and structural advances in Version 4 of the Community Land Model. J Adv Model Earth Syst 3, M03001. doi:10.1029/2011MS000045

Livingstone DM (2003) Impact of secular climate change on the thermal structure of a large temperate Central European lake. Clim Chang 57:205-225. doi:10.1023/a:1022119503144

Magnuson JJ, Robertson DM, Benson BJ, Wynne RH, Livingstone DM, Arai T, Assel RA, Barry RG, Card V, Kuusisto E, Granin NG, Prowse TD, Stewart KM, Vuglinski VS (2000) Historical trends in lake and river ice cover in the northern hemisphere. Science 289:1743-1746. doi:10. $1126 /$ science. 289.5485 .1743 
Martynov A, Sushama L, Laprise R (2010) Simulation of temperate freezing lakes by one-dimensional lake models: performance assessment for interactive coupling with regional climate models. Boreal Environ Res $15: 143-164$

Mearns LO, Gutowski WJ, Jones R, Leung LY, McGinnis S, Nunes AMB, Qian Y (2009) A regional climate change assessment program for North America. Eos 90:311-312. doi:10.1029/2009EO360002

Meerhoff M, Clemente JM, De Mello FT, Iglesias C, Pedersen AR, Jeppesen E (2007) Can warm climate-related structure of littoral predator assemblies weaken the clear water state in shallow lakes? Glob Chang Biol 13: 1888-1897. doi:10.1111/j.1365-2486.2007.01408.x

Nordbo A, Launiainen S, Mammarella I, Leppäranta M, Huotari J, Ojala A, Vesala T (2011) Long-term energy flux measurements and energy balance over a small boreal lake using eddy covariance technique. J Geophys Res 116, DO2119. doi:10.1029/2010JD014542

Paerl HW, Hall NS, Calandrino ES (2011) Controlling harmful cyanobacterial blooms in a world experiencing anthropogenic and climatic-induced change. Sci Total Environ 409:1739-1745. doi:10.1016/j.scitotenv. 2011.02.001

Perroud M, Goyette S, Martynov A, Beniston M, Anneville O (2009) Simulation of multiannual thermal profiles in deep Lake Geneva: a comparison of one-dimensional lake models. Limnol Oceanogr 54:1574-1594. doi: $10.4319 / 10.2009 .54 .5 .1574$

Persson I, Jones ID (2008) The effect of water colour on lake hydrodynamics: a modelling study. Freshw Biol 53 : 2345-2355. doi:10.1111/j.1365-2427.2008.02049.x

Rahel FJ, Olden JD (2008) Assessing the effects of climate change on aquatic invasive species. Conserv Biol 22: 521-533. doi:10.1111/j.1365-2427.2009.02280.x

Rempfer J, Livingstone DM, Blodau C, Forster R, Niederhauser P, Kipfer R (2010) The effect of the exceptionally mild European winter of 2006-2007 on temperature and oxygen profiles in lakes in Switzerland: a foretaste of the future? Limnol Oceanogr 55:2170-2180. doi:10.4319/lo.2010.55.5.2170

Rühland K, Paterson AM, Smol JP (2008) Hemispheric-scale patterns of climate-related shifts in planktonic diatoms from North American and European lakes. Glob Chang Biol 14:2740-2754. doi:10.1111/j.13652486.2008.01670.x

Schmid M, Hunziker S, Wüest A (2014) Lake surface temperatures in a changing climate: a global sensitivity analysis. Clim Chang 124:301-315. doi:10.1007/s10584-014-1087-2

Stefan HG, Hondzo M, Fang X, Eaton JG, McCormick JH (1996) Simulated long-term temperature and dissolved oxygen characteristics of lakes in the north-central United States and associated fish habitat limits. Limnol Oceanogr 41:1124-1135. doi:10.4319/lo.1996.41.5.1124

Stepanenko V, Martynov A, Jöhnk KD, Subin ZM, Perroud M, Fang X, Beyrich F, Mironov D, Goyette S (2013) A one-dimensional model intercomparison study of thermal regime of a shallow, turbid midlatitude lake. Geosci Model Dev 6:1337-1352. doi:10.5194/gmd-6-1337-2013

Strecker AL, Cobb TP, Vinebrooke RD (2004) Effects of experimental greenhouse warming on phytoplankton and zooplankton communities in fishless alpine ponds. Limnol Oceanogr 49:1182-1190. doi:10.4319/lo. 2004.49.4.1182

Subin ZM, Riley WJ, Mironov D (2012) An improved lake model for climate simulations: model structure, evaluation, and sensitivity analyses in CESM1. J Adv Model Earth Syst 4(M02001):2012. doi:10.1029/ 2011MS000072

Tanentzap AJ, Yan ND, Keller B, Girard R, Heneberry J, Gunn JM, Hamilton DP, Taylor DA (2008) Cooling lakes while the world warms: effects of forest regrowth and increased dissolved organic matter on the thermal regime of a temperate, urban lake. Limnol Oceanogr 53:404-410. doi:10.4319/lo.2008.53.1.0404

U.S. EPA (Environmental Protection Agency) (2008) Using the BASINS meteorological database-version 2006. BASINS Technical Note 10. Office of Water

U.S. EPA (Environmental Protection Agency) (2009) National lakes database: a collaborative survey of the nation's lakes. EPA 841-R-09-001. Office of Water and Office of Research and Development

U.S. EPA (Environmental Protection Agency) (2013) Watershed modeling to assess the sensitivity of streamflow, nutrients, and sediment loading to potential climate change and urban development in 20 U.S. Watersheds. EPA/600/R12/058F. National Center for Environmental Assessment, Office of Research and Development

Wilhelm S, Adrian R (2008) Impact of summer warming on the thermal characteristics of a polymictic lake and consequences for oxygen, nutrients and phytoplankton. Freshw Biol 53:226-237. doi:10.1111/j.1365-2427. 2007.01887.x

Wismer DA, Christie AE (1987) Temperature relationships of Great Lakes fishes: a data compilation. Great Lakes Fisheries Commission Special Publication No. 87-3

Woodward G, Perkins DM, Brown LE (2010) Climate change and freshwater ecosystems: impacts across multiple levels of organization. Phil Trans R Soc B 365:2093-2106. doi:10.1098/rstb.2010.0055 